\title{
A genética humana nos livros didáticos brasileiros e o determinismo genético
}

\author{
Human genetics in Brazilian textbooks \\ and genetic determinism
}

Luana de Souza Prochazka ${ }^{1}$. Fernanda Franzolin ${ }^{1}$

\begin{abstract}
Resumo: O tratamento da genética humana no ensino de genética pode ter por objetivo aproximar o assunto da realidade do aluno e ilustrar que os mecanismos gênicos não são exclusivos de outras espécies. Sendo os livros didáticos um dos principais recursos utilizados na escola, esta pesquisa teve por objetivo verificar quais características humanas são mencionadas nos livros didáticos brasileiros e como são abordadas, propiciando ou não ao aluno a compreensão da complexidade da expressão de suas características. Foram analisados livros aprovados pelo Programa Nacional do Livro Didático, quantificando as características humanas citadas e categorizando-as de acordo com o seu modo de tratamento. Os resultados demonstram que as características são menos priorizadas dentro dos livros didáticos; são em sua maioria descritas como monogênicas; e estão pouco relacionadas com informações sobre a influência do ambiente em sua expressão, podendo propiciar uma visão determinista da genética.
\end{abstract}

Palavras chave: Determinismo genético. Ensino de biologia. Genética humana. Livro didático. Programa Nacional do Livro Didático.

\begin{abstract}
In teaching genetics, addressing human genetics may bring the subject matter closer to students and illustrate that genetic mechanisms are not exclusive to other species. Since textbooks are among the main resources used in schools, the objective of this study is to verify which human characteristics are mentioned in textbooks and how they are addressed, and whether they provide students with an understanding of the complexity of the expression of their characteristics. In this study, we analyze books approved by the National Textbook Program, quantifying the human characteristics cited and categorizing them according to approach. The results show that human characteristics appear less frequently than other examples of inheritance; they are mostly described as single-gene characteristics, and this information is only sparsely related to the influence of the environment on genetic expression, which may provide a deterministic overview of genetics.
\end{abstract}

Keywords: Genetic determinism. Biology teaching. Human genetics. School textbook. National Program of School Textbooks.

\footnotetext{
${ }^{1}$ Universidade Federal do ABC (UFABC), Centro de Ciências Naturais e Humanas, Santo André, SP, Brasil. Orcid: <https://orcid.org/0000-0002-7443-3963>. E-mail: <luana.prochazka@ufabc.edu.br>.
} 


\section{Introdução}

Um dos objetivos da escola é o de formar cidadãos e o ensino da Biologia tem uma posição de destaque nessa tarefa (KRASILCHIK, 2008). A formação biológica visa a que o cidadão seja capaz de tomar decisões no âmbito individual e coletivo num contexto ético, de responsabilidade e respeito, inserindo-se também no mundo da ciência e da tecnologia (BRASIL, 2000; KRASILCHIK, 2008).

A Biologia, como disciplina específica, começa a ser ofertada aos alunos no 1. ${ }^{\circ}$ ano do Ensino Médio e, ao longo dos três anos de curso, diversos temas e aspectos referentes a essa área de conhecimento são abordados. Geralmente, no 2. ${ }^{\circ}$ ou $3 .^{\circ}$ anos do Ensino Médio são inseridos assuntos relacionados à genética. De acordo com os Parâmetros Curriculares Nacionais para o Ensino Médio (PCNEM) (BRASIL, 2000), os conteúdos de genética devem ser abordados de modo a discutir seus pressupostos, seus limites e o contexto em que foram formulados, de modo a permitir a compreensão histórica da produção científica e promover o entendimento da transmissão das características. Assim, através da genética, também são abordados conteúdos mais específicos, como a genética humana, interesse desta pesquisa.

Em um contexto científico, no século XIX, o cientista Francis Galton (1822-1911) realizou uma pesquisa relacionada ao que posteriormente, no século XX, foi chamado de genética humana. Ele pesquisou a herança de características quantitativas de variação contínua, cujos resultados foram publicados em 1869. Ele também realizou estudos sobre hereditariedade em gêmeos e, mesmo inicialmente dando grande importância à herança, passou a reconhecer e estudar a relativa importância da hereditariedade e do ambiente (BULMER, 2003). Após Galton, muitos outros cientistas e pesquisadores se envolveram em estudos relacionados à genética humana, como, por exemplo, Charles B. Davenport (1866-1944); e hoje, um dos assuntos mais recentes relacionados a essa área é o Projeto Genoma Humano (BORGES-OSÓRIO; ROBINSON, 2013).

Já no contexto escolar, segundo Casagrande (2006), a genética humana aborda principalmente exemplos de como a genética está presente no contexto humano. Essa perspectiva tem como propósito explorar com os alunos que os mecanismos gênicos não são exclusivos de outras espécies. Este aspecto é importante no ensino, pois, a partir dele, é possível contextualizar os mecanismos de herança e alterações gênicas, capacitando o aluno a visualizar os conteúdos de genética básica nas questões de seus interesses pessoal e coletivo.

Dentro desse contexto, autores mencionam que um dos recursos mais utilizados nas salas de aula brasileiras são os livros didáticos. Eles são utilizados pelos professores com o intuito de selecionar e organizar os conteúdos que serão desenvolvidos com os alunos ao longo do ano letivo (CICILLINI, 1998; FRACALANZA; AMARAL; GOUVEIA, 1987; OSSAK, 2006; SELLES; FERREIRA, 2004). Dessa forma, desde 1929, existem políticas públicas que visam a distribuição de obras didáticas na Rede Pública de Ensino; porém, somente em 1993/1994 foram definidos os critérios para avaliação dos livros didáticos e, em 1996, foi iniciado o processo de avaliação pedagógica dos livros inscritos no Programa Nacional do Livro Didático (PNLD) (FUNDO NACIONAL DE DESENVOLVIMENTO DA EDUCAÇÃO, 2015). Atualmente, as coleções dos livros didáticos destinados ao Ensino Médio são avaliadas a cada três anos, tendo as últimas avaliações para o Ensino Médio ocorrido em 2012 e 2015. Muitos pesquisadores (FRACALANZA; AMARAL; GOUVEIA, 1987; NASCIMENTO; MARTINS, 2005) também 
acreditam na importância de ter os livros didáticos como objeto de estudo. Acreditamos que o estudo e a análise desses livros podem trazer contribuições importantes para as futuras edições.

Realizando uma busca nas pesquisas brasileiras, foram encontrados poucos trabalhos que abordam o tema da genética humana nos livros didáticos. Os que se concentram nessa área tratam de grupos sanguíneos (BATISTETI et al., 2007; PSCHISKY; MAESTRELLI; FERRARI, 2003), anemia falciforme (CARMO; ALMEIDA; ARTEAGA, 2013), biotecnologia e bioética referentes a fertilização in vitro (TIZIOTO; ARAÚJO, 2007) e doenças genéticas (CASAGRANDE, 2006). Notamos que as pesquisas realizadas no âmbito nacional estão focadas em pontos bem específicos; por outro lado, observamos que pesquisas realizadas em outros países (principalmente os europeus) analisam nos livros didáticos questões mais gerais e as relacionam com questões sobre determinismo genético e transposição didática (CASTÉRA et al., 2008; CLÉMENT; CASTÉRA, 2013; SILVA; FERREIRA; CARVALHO, 2009, 2010, 2011).

O determinismo genético admite que as características de um indivíduo são somente influenciadas pelo gene, sendo fixas em sua caracterização fenotípica e pouco ou nada afetadas por mudanças no ambiente físico e social (PENCHASZADEH, 2004). Tal concepção é questionada atualmente. Muitos estudos demonstram que a expressão de uma característica não depende apenas de um gene específico. Lewontin, Rose e Kamin (1985) também afirmam que a maioria das características de cada organismo são influenciadas por interações entre genes e o ambiente.

Levando essas informações em consideração, autores como Bizzo (1998), Camargo e Infante-Malachias (2007), Dougherty (2009), Trivelato (1988), entre outros, defendem que o ensino das heranças genéticas não pode ser tratado apenas com casos simples de herança monogênica. A importância dos fatores ambientais para a expressão das características em cada indivíduo deve ser esclarecida. Bizzo (1998), por exemplo, defende a importância de ensinar penetrância e expressividade com o intuito de o aluno compreender que não basta possuir um gene, pois o ambiente tem grande influência na determinação de características. Hoje, também sabemos que a maioria das características humanas não são determinadas por um padrão de herança simples, no qual a atuação de um par de genes é suficiente para explicar a expressão de uma característica (DOUGHERTY, 2009). Compreender como ocorre a expressão de características complexas significa compreender diversos aspectos de saúde pública, como câncer, diabetes, doenças cardíacas e as demais características presentes nos seres humanos. Essa preocupação com o ensino de uma genética menos determinista vem se refletindo nas pesquisas europeias (CASTÉRA et al., 2008; CLÉMENT; CASTÉRA, 2013; SILVA; FERREIRA; CARVALHO, 2009, 2010, 2011).

Assim, levando em consideração a importância do ensino de genética humana para que os alunos da educação básica possam compreender suas próprias características, tornase relevante a investigação de como esse conteúdo está inserido nos livros didáticos e se sua abordagem é determinista ou não. Desse modo, esta pesquisa teve por objetivo analisar livros didáticos brasileiros com o intuito de verificar quais características humanas são mencionadas nos livros didáticos brasileiros e como são abordadas, propiciando ou não ao aluno a compreensão da complexidade da expressão de suas características. Com base nesse objetivo principal, esta pesquisa procura responder às seguintes perguntas: (1) Qual é a prioridade dada ao tratamento das características humanas dentro do ensino de genética pelos livros didáticos de Ensino Médio brasileiros?; (2) quais características são mais frequentemente mencionadas?; (3) Como estas 
características são tratadas quanto aos fatores que influenciam sua expressão, ou seja, a qual tipo de herança essas características estão sendo relacionadas (monogênica ou poligênica)?; (4) Os livros didáticos associam a influência do ambiente à sua expressão?

\section{Metodologia}

\section{Constituição da amostra}

Os nove livros aqui analisados passaram por um processo de avaliação do Governo Federal, tendo sido aprovados pelo Programa Nacional do Livro Didático (PNLD), nas edições de 2012 e 2015. Assim, foram analisados três livros do PNLD 2012 e seis livros do PNLD 2015 (Anexo A). A aprovação destes livros pelo PNLD permite que eles sejam distribuídos na rede pública de ensino, procurando atender a escolha dos professores de cada escola. Os livros foram concedidos por professores de escolas públicas conforme a disponibilidade de cada material. Esta é a razão de a amostra ser composta de livros das duas avaliações, já que a análise dos livros ocorreu em um momento de transição entre as distribuições decorrentes dos dois processos avaliativos. Todos os livros analisados correspondem à versão do professor. A identificação dos livros está expressa pelo seu ISBN, no apêndice I. Dessa forma, as nove coleções analisadas serão denominadas de A, B, C, D, E, F, G, H e I. As coleções A, B e C são referentes ao PNLD 2012 e as demais, referentes ao PNLD 2015.

\section{Compilação e análise dos dados}

Para análise dos livros, foram selecionados todos os capítulos destinados aos conteúdos de genética (incluindo Biologia Molecular). Estes geralmente são encontrados no $3 .^{\circ}$ volume das coleções, destinado ao $3 .^{\circ}$ ano do Ensino Médio, mas também podem ser encontrados no $2 .^{\circ}$ volume. Foram buscadas citações sobre características humanas nestes capítulos, incluindo doenças e síndromes.

Para verificar qual é a prioridade dada ao tratamento das características humanas dentro do ensino de genética pelos livros didáticos, procuramos utilizar a metodologia aplicada por Silva, Ferreira e Carvalho (2009), que envolve a contagem das páginas relacionadas ao ensino de genética humana e a comparação desse dado com a quantidade de páginas destinadas ao ensino de genética em geral. Essa metodologia foi julgada pertinente, pois atendia a nossa intenção de verificar o quanto de atenção às características humanas é dedicada pelos autores dentro do ensino de genética, permitindo ao aluno compreender que os conceitos relacionados a esse conteúdo também estão associados aos seres humanos, como ele próprio, e não somente a outros organismos. Não era objetivo deste estudo verificar o quanto a genética estava sendo priorizada com relação a outros tópicos ensinados no Ensino Médio, apesar de esse aspecto ser relevante e poder ser foco de investigação de outras pesquisas.

A verificação de quais características humanas são mais frequentemente mencionadas e como elas são tratadas quanto aos fatores que influenciam sua expressão foi baseada em Marshall e Rossman (2006), que sugerem, para análise de dados qualitativos, a organização dos 
dados, a imersão e a criação das categorias. Desse modo, primeiramente foi realizada a leitura dos capítulos selecionados para análise. Durante esse momento, toda vez que se identificava a menção a uma característica humana, a ocorrência era registrada em uma tabela. Cada linha da tabela referia-se a uma ocorrência identificada e, em suas respectivas colunas, foram registrados: código do livro, capítulo, página, nome da característica, padrão de herança relacionado e observações. Essa tabela serviu para a quantificação dos registros e a construção de gráficos, permitindo uma comparação quantitativa, bem como a interpretação dos dados.

Os padrões de herança identificados foram registrados de formas variadas, seguindo as denominações apresentadas pelos autores, tais como: dominância completa, codominância, codominância, pleitropia, alelos múltiplos, interação gênica, entre outros. Posteriormente, foi realizada uma imersão nos dados, ou seja, a sua leitura e releitura, quantas vezes fossem necessárias, até que as categorias finais fossem delineadas, levando em consideração o objetivo desta pesquisa. Dessa forma, para continuação da análise, estes padrões foram agrupados nas seguintes categorias de herança: monogênica; poligênica; e herança relacionada ao sexo. Ainda foram registradas aquelas em que o autor não as associava a um padrão de herança, mas sim às anomalias cromossômicas, bem como a sua taxa de concordância na ocorrência entre gêmeos. Também foi verificado e registrado se o livro fazia menção à influência do ambiente na expressão dessas características. Como essas categorias não são excludentes, algumas ocorrências foram inseridas em mais de uma categoria.

Isso aconteceu principalmente quando diferentes autores atribuíram a essas características mais de uma forma de herança.

\section{Resultados e Discussão}

Após a contagem das páginas para verificar qual é a prioridade dada ao tratamento das características humanas dentro do ensino de genética pelos livros didáticos, foi verificado que a média da porcentagem de páginas destinada aos traços humanos em relação ao número total de páginas destinadas à genética é de aproximadamente 18\% (Tabela 1). Esse dado está próximo ao encontrado por Silva, Ferreira e Carvalho (2009) ao analisar livros de 14 países, incluindo Portugal, França, Alemanha e Itália, entre outros. Nove destes países tinham médias inferiores ou próximas a 20\%. Apenas a Finlândia e Chipre se destacavam dos demais, com uma porcentagem próxima a 40\%. Portanto, é possível notar que, no Brasil, assim como em outros países, ainda pouca importância é dedicada ao ensino de genética humana dentro do ensino de genética. Em pesquisa anterior (FRANZOLIN, 2012), verificou-se que uma grande preocupação dos professores é ensinar genética para que os alunos compreendam suas próprias características. Todavia, essa compreensão pode ficar comprometida caso os exemplos utilizados nas escolas apresentem pouca proximidade com os próprios alunos. Concordamos com Casagrande (2006) sobre a importância de explorar com os estudantes que os mecanismos gênicos não são exclusivos de outras espécies. Desse modo, aumentar a atenção dada ao ensino de genética humana poderia ajudá-los a compreender como os conceitos de genética aprendidos na escola têm relação com eles próprios. 
Tabela 1. Número de páginas analisadas por livro e porcentagem de páginas destinadas à genética humana

\begin{tabular}{lccc}
\hline Livro & $\begin{array}{c}\text { Total de páginas } \\
\text { para genética }\end{array}$ & $\begin{array}{c}\text { Total de páginas para } \\
\text { genética humana }\end{array}$ & $\begin{array}{c}\text { Porcentagem das páginas } \\
\text { para genética humana }\end{array}$ \\
\hline A & 122 & 25 & $20,49 \%$ \\
B & 106 & 19 & $17,92 \%$ \\
C & 117 & 30 & $25,64 \%$ \\
D & 79 & 16 & $20,25 \%$ \\
E & 127 & 15 & $11,81 \%$ \\
F & 123 & 30 & $24,39 \%$ \\
G & 93 & 17 & $18,28 \%$ \\
H & 103 & 15 & $14,56 \%$ \\
I & 137 & 17 & $12,41 \%$ \\
Total & 1007 & 184 & $18,27 \%$ \\
\hline
\end{tabular}

Fonte: elaborado pelas autoras.

Reforçando a importância dessa forma de abordagem, os dados de Trivelato (1988) mostram que exemplos relacionados a seres humanos deixam os alunos mais interessados no ensino de genética. Os estudantes acabam se envolvendo em discussões, provavelmente motivados pelo conhecimento de suas próprias características. Todavia, seus resultados mostram que os alunos ficam perplexos e incapazes de aplicar a seres humanos fenômenos genéticos exemplificados com ervilhas, abóboras ou coelhos. Dessa forma, a autora defende que o enfoque tradicional seja revisto, dando abertura para temas de interesse dos alunos. Entretanto, após três décadas, os dados da presente pesquisa mostram que essa contextualização precisa ser melhorada nos livros didáticos.

Contudo, como afirma Trivelato (1988), apenas a presença de exemplos relacionados a seres humanos não é suficiente, pois é também importante que esse tratamento seja de qualidade. Isso significa levar os estudantes a reflexões sobre valores e permitir-lhes a compreensão de questões atuais relacionadas a sua tomada de decisão. Em seus estudos, a pesquisadora pode perceber a influência de preconceitos raciais, normas de comportamento e regras morais nas discussões relacionadas à genética humana. Também notou que a professora observada em sua pesquisa tinha dificuldades para perceber e trabalhar esses valores. Ela usava os exemplos de genética humana, porém dava a impressão de que sua principal preocupação não era preparar os alunos para decisões futuras.

Após a análise qualitativa e quantitativa para verificar quais características são mais frequentemente mencionadas, notamos que, das citações correspondentes a características, doenças e síndromes humanas, cinco foram encontradas em todos os livros analisados: albinismo, daltonismo, hemofilia, sistema $A B O$ e sistema rH (Tabela 2). 
A genética humana nos livros didáticos brasileiros ...

Tabela 2. Características citadas em mais de quatro livros

\begin{tabular}{lc}
\hline \multicolumn{1}{c}{ Característica } & $\begin{array}{c}\text { Número de livros } \\
\text { onde houve citação }\end{array}$ \\
\hline Albinismo & 9 \\
Daltonismo & 9 \\
Hemofilia & 9 \\
Sistema ABO & 9 \\
Sistema rh & 9 \\
Cor da Pele & 8 \\
Cor dos olhos & 8 \\
Estatura humana & 8 \\
Fenilcetonúria & 8 \\
Anemia falciforme & 7 \\
Calvície & 7 \\
Fibrose cística & 7 \\
Hipertricose auricular & 7 \\
Síndrome de Turner & 7 \\
Sistema MN & 7 \\
Acondroplasia & 6 \\
Síndrome de Klinefelter & 6 \\
Distrofia Muscular & 5 \\
Lobo da Orelha & 5 \\
Polidactilia & 5 \\
Síndrome de Down & 5 \\
Total & 21 \\
\hline Sor elbor & \\
\hline
\end{tabular}

Fonte: elaborado pelas autoras.

Posteriormente, também estão entre as mais mencionadas a cor da pele, dos olhos, a estatura bumana e a presença de fenilcetonúria. Consideramos importante identificar quais são essas características para priorizá-las no aprofundamento de estudos sobre o seu tratamento. Diante desses dados, dedicamo-nos a outra pesquisa para investigar o processo de didatização de três dessas características: cor de pele, cor dos olhos e estatura humana. Esses dados são importantes porque nos permitiram observar quais são os exemplos mais frequentemente mencionados. Chama a atenção o fato de que, no ensino de genética, não é frequente a menção à expressão de características como diabetes, hipertensão, obesidade ou câncer. Estas se expressam a partir de um fator genético com influência ambiental e são comuns na população, sendo de grande preocupação para a saúde pública.

Analisando os livros individualmente, notamos uma variação quanto à quantidade de características apresentadas em cada livro. O livro C, com o maior número de exemplos, 
apresentou 39 características e o livro E, com o menor número, apresentou 15 (Figura 1). A média encontrada foi de aproximadamente 28 características por livro, com um desvio padrão de 7,65. Tais dados indicam que a quantidade de características em cada livro analisado varia em aproximadamente $27 \%$, valor do coeficiente de variação. Portanto, os dados não são homogêneos entre todos os livros e há uma variação com relação à média que consideramos razoável. Portanto, interpretamos que a preocupação em citar características humanas é diferente entre autores, tendo autores razoavelmente mais preocupados do que a média e outros razoavelmente menos preocupados em relação à média.

Figura 1. Total de características presentes em cada livro

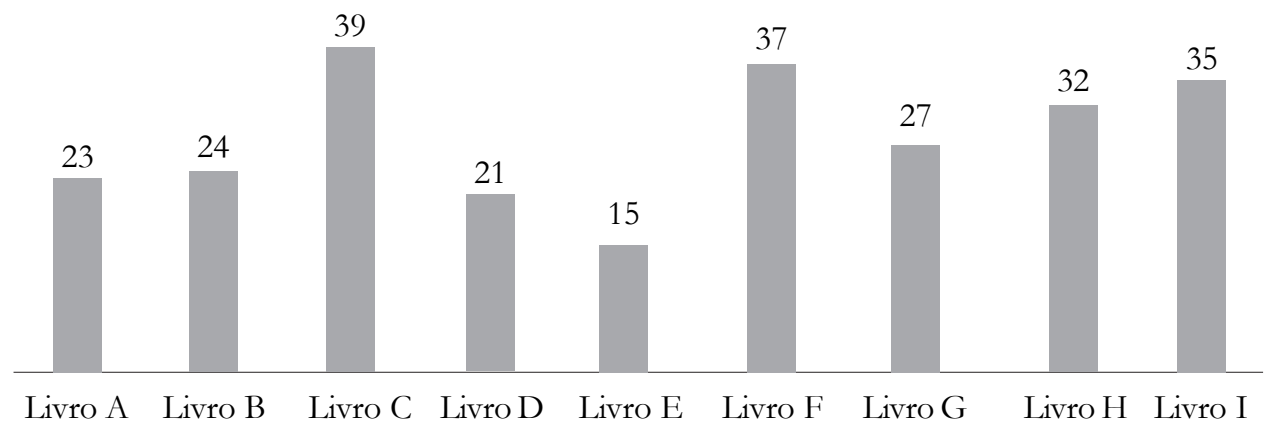

Fonte: elaborado pelas autoras.

Após a imersão nos dados para verificar como as 84 ocorrências de características humanas encontradas são tratadas quanto aos fatores que influenciam sua expressão, elas foram inseridas em cinco categorias, sendo elas: (1) Características monogênicas, agrupando as características que são mencionadas como determinadas por apenas um par de gene; (2) Características poligênicas, agrupando características que são citadas como determinadas por mais de um par de gene; (3) anomalias cromossômicas, reunindo características que são apresentadas relacionadas a mutações de algum cromossomo; (4) Herança ligada aos cromossomos sexuais, agrupando as características que estão diretamente relacionadas com os cromossomos sexuais; e (5) Taxa de Concordância, que são aquelas características para as quais, devido a estudos com gêmeos monozigóticos, se estabeleceu uma porcentagem entre a influência do ambiente e o gene para a expressão de uma característica. Ao fim dessa categorização, foi verificado que a maioria dos exemplos de genética humana inseridos nos livros didáticos são apresentados como monogêni$\cos (51 \%, \mathrm{n}=43)$, seguidos pelos exemplos de características ligadas aos cromossomos sexuais $(19 \%, n=16)$ (Figura 2). Apenas 13\% das características mencionadas $(n=11)$ foram apresentadas como poligênicas. Cabe aqui ressaltar que a maioria do fenótipo humano é o resultado de interações complexas entre as forças hereditárias e ambientais (PAPALIA; FELDMAN, 2013); logo, os exemplos que mais são apresentados nos livros didáticos não refletem a complexidade 
da herança genética, podendo dificultar a sua compreensão, dando a impressão ao aluno de que a maioria de suas características são monogênicas.

Figura 2. Quantidade de características encontradas para cada categoria

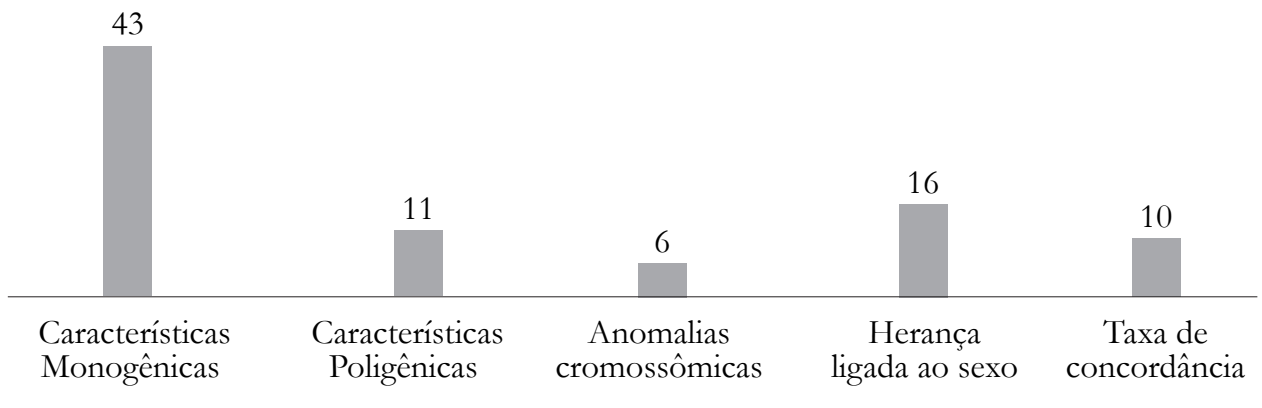

Fonte: elaborado pelas autoras.

Devido à importância do ambiente para a expressão de um fenótipo, procuramos averiguar se, na apresentação das características humanas nos livros didáticos, havia uma preocupação de explicar que o ambiente pode influenciar na expressão de um fenótipo. Notamos que, das 84 ocorrências de menções de características humanas encontradas ao longo da análise, em $18(21,43 \%)$ os autores informaram ao leitor que o ambiente pode influenciar na expressão da característica no indivíduo. Dentro dessas ocorrências, foram citadas características como alcoolismo, alergia, mal de Alzheimer, câncer, ser canhoto ou destro, cor da pele e dos olhos, depressão, diabetes, distúrbios psiquiátricos, enrolar as bordas da língua em forma de U, epilepsia, estatura humana, hipertensão, individualidade do ser humano, obesidade, mal de Parkinson e tabagismo. As dez ocorrências inseridas na categoria taxa de concordância também foram consideradas nessa contagem, sendo que todas elas foram apresentadas pelo livro $\mathrm{H}$. Dessa forma, mais da metade das ocorrências relacionadas à influência do meio na expressão das características humanas estavam em apenas um livro. Esse resultado já mostra alguma preocupação dos autores em evitar uma visão determinista da genética. Mas seria importante pensar em possibilidades de ampliar essa porcentagem, para que o aluno realmente compreendesse o quanto fatores ambientais podem influenciar na expressão de suas características, não ficando com a impressão de que isso ocorre em poucos casos.

Diante desses resultados, acreditamos que os livros didáticos do Ensino Médio carecem de exemplos que forneçam aos alunos uma visão menos determinista da genética humana. É possível que os autores deixem clara a influência do ambiente na expressão gênica em outros locais do livro, não só nas páginas em que estão tratando de traços humanos, o que não foi foco da análise desta pesquisa, já que esta tinha como principal foco as características humanas. Todavia, o conjunto dos exemplos apresentados geralmente reforça a ideia de que basta alguém ser portador de um alelo mutante para um gene específico, para ele obrigatoriamente apresentar 
a característica relacionada a este alelo. Ademais, muito pouco é explicado sobre a complexidade da expressão gênica na determinação dos traços humanos.

Tais resultados vão ao encontro dos obtidos por Silva, Ferreira e Carvalho (2009, 2010, 2011), que analisaram livros de diversos países e constataram que doenças consideradas estritamente genéticas são maioria nos livros dos vários países analisados. Comparando com os dados desta pesquisa, foi observado que as doenças mais citadas são praticamente as mesmas. Esses resultados, apesar de não serem uma particularidade brasileira, são preocupantes, pois a ciência tem outras explicações que vão além do padrão monogênico abordado no ensino de genética clássica. Se a maioria das características humanas são determinadas por um padrão complexo de expressão, por que restringir-se a um conteúdo simplista dentro dos livros didáticos? Por que não ampliar os exemplos relacionados às características humanas que são consideradas multifatoriais? Ou às diversas vias de controle dos genes? Por que não falar sobre epigenética, e as questões de penetrância incompleta? Todos esses conhecimentos vão ao encontro de uma visão menos determinista, que já é defendida por vários autores (CANGUILHEM, 2009; JACQUARD, 1988; JACQUARD; KAHN, 2001; LEWONTIN; ROSE; KAMIN, 1985). Além do mais, segundo Silva, Ferreira e Carvalho (2010, p. 340), mencionar que uma característica ou doença pode ocorrer em um indivíduo dependendo da influência do ambiente é importante para a promoção da saúde, já que "uma vez que a doença genética é apresentada como um determinismo genético, sem influência do ambiente, o indivíduo pouco ou nada pode fazer para manter e/ou melhorar a sua saúde". Ao contrário, caso o indivíduo tenha a informação sobre a influência do ambiente, ele pode procurar melhorar o seu estilo de vida de forma a evitar as condições propicias ao desenvolvimento de uma doença.

Uma possível explicação para esses resultados está relacionada com o longo processo de transposição didática. Castéra et al. (2008) observaram em sua pesquisa que os conteúdos de genética humana em livros didáticos de diversos países ainda encaram a genética humana com um certo reducionismo de conceitos, de forma que conteúdos sobre epigenética e a relação gene-ambiente ainda são pouco explorados. Todavia, as pesquisas atuais apontam que a grande maioria das características humanas não são determinadas apenas pela expressão de um par de genes (DOUGHERTY, 2009). Chevallard (1991) ainda diz que o processo de transposição didática, apesar de necessário, pode gerar “disfunções inadequadas". Por isso, os materiais didáticos sempre devem passar por uma avaliação com o intuito de reduzir problemas decorrentes desse processo de didatização, permitindo, dessa forma, reflexões sobre o que é importante ensinar na escola e como ensinar.

\section{Conclusão}

Ao analisar livros didáticos brasileiros com o intuito de verificar o quanto as características humanas são mencionadas e se sua abordagem propicia ou não ao aluno a compreensão da complexidade da expressão de suas características, os resultados aqui obtidos demonstram que ainda pouca importância é dedicada ao ensino de genética humana dentro do ensino de genética. Portanto, percebemos que é importante aumentar a atenção a este tópico para permitir aos alunos a compreensão de como os conceitos de genética aprendidos na escola têm relação com eles próprios, aproximando esse conteúdo de suas vivências e permitindo-lhes compreender seu corpo e a si próprios. 
Ademais, verificamos que, na maioria das ocorrências de características humanas nos livros didáticos de Biologia brasileiros, estas são abordadas como monogênicas e que, das 84 ocorrências encontradas nos livros, apenas 18 relatam a influência do ambiente para a expressão do traço. Tais resultados não são específicos dos livros didáticos brasileiros; ao contrário, elas vão ao encontro de outras pesquisas realizadas com livros didáticos de outros países.

Portanto, concluímos que os livros ainda precisam associar mais os exemplos de genética humana à complexidade da expressão gênica e à influência do ambiente, para evitar uma visão determinista da genética. Devemos nos atentar para o fato de que a maioria das características humanas não é de origem monogênica, ou seja, não é determinada devido à ação de apenas um gene. Apresentar nas escolas apenas essa visão reducionista da genética impede que o aluno tenha um panorama geral dos conceitos genéticos, dificultando-o a tomar decisões individuais e coletivas de maneira consciente. Além do mais, dentre as características mais citadas pelos autores estão albinismo, daltonismo, hemofilia, sistema $\mathrm{ABO}$, sistema $\mathrm{rH}$, cor da pele, dos olhos, estatura humana e fenilcetonúria. São raras ao aluno informações sobre doenças que não são estritamente genéticas, como diabetes, obesidade e câncer, que estão muito presentes no seu dia-a-dia.

Sendo assim, é importante que os autores dos livros didáticos, bem como os professores que utilizam desses materiais, se preocupem em contextualizar a genética, ampliando a abordagem da genética humana e atualizando os conteúdos de genética, evitando considerações simplistas sobre a expressão das características humanas. Dessa forma, enfatizarão aos alunos que as suas características não são apenas geneticamente determinadas ou predominantemente monogênicas, e que questões físicas, bioquímicas e ambientais podem e vão influenciar as características de cada indivíduo.

\section{Referências}

BATISTETI, C. B. et al. A abordagem histórica do sistema do grupo sanguíneo ABO nos livros didáticos de ciências e biologia. In: ENCONTRO NACIONAL DE PESQUISA EM EDUCAÇÃO EM CIÊNCIAS, 6., 2007, Florianópolis. Anais... Florianópolis: ABRAPEC, 2007. Disponível em: <http://www.nutes.ufrj.br/abrapec/vienpec/CR2/p818.pdf>. Acesso em: 20 dez. 2017.

BIZZO, N. O paradoxo social-eugênico e os professores: ontem e hoje. In: CHASSOT, A.; OLIVEIRA, J. R. (Org.). Ciência, ética e cultura na educação. São Leopoldo: UNISINOS, 1998. p. 165-189.

BORGES-OSÓRIO, R.; ROBINSON, W. M. Genética humana. 3. ed. Porto Alegre: Artmed, 2013.

BRASIL. Ministério da Educação. Secretaria de Educação Média e Tecnológica. Parâmetros curriculares nacionais: ensino médio: ciências da natureza, matemática e suas tecnologias. Brasília, 2000. 
BULMER, M. G. Francis Galton: pioneer of heredity and biometry. Baltimore: Johns Hopkins University Press, 2003.

CAMARGO, S. S.; INFANTE-MALACHIAS, M. E. A genética humana no ensino médio: algumas propostas. Genética na Escola, Ribeirão Preto, v. 2, n. 1, p. 14-16, 2007. Disponível em: <http://docs.wixstatic.com/ugd/b703be_213a6a6514ba4157b7327c516b634d33.pdf>. Acesso em: 20 dez. 2017.

CANGUILHEM, G. O normal e o patológico. 6. ed. Rio de Janeiro: Forense Universitária, 2009.

CARMO, J. S.; ALMEIDA, R. O.; ARTEAGA, J. S. Abordagens de anemia falciforme em livros didáticos de biologia: em foco racismo científico e informações estigmatizantes relacionadas à doença. In: ENCONTRO NACIONAL DE PESQUISA EM EDUCAÇÃO EM CIÊNCIAS, 9., 2007, Águas de Lindóia. Atas... Águas de Lindóia: ABRAPEC, 2013. p. 1-8.

CASAGRANDE, G. L. A genética humana no livro didático de biologia. 2006. 103 f. Dissertação (Mestrado em Educação Científica e Tecnológica) - Faculdade de Educação, Universidade Federal de Santa Catarina, Florianópolis, 2006.

CASTÉRA, J. et al. Genetic determinism in school textbooks: a comparative study conducted among sixteen countries. Science Education International, Izmir, v. 19, n. 2, p. 163-184, jun. 2008.

CHEVALLARD, Y. La transposición didáctica: del saber sabio al saber enseñado. 3. ed. Buenos Aires: Aique, 1991.

CICILLINI, G. A. Ensino de biologia: o livro didático e a prática pedagógica dos professores no ensino médio. Ensino em Re-vista, Uberlândia, v. 6, n. 1, p. 29-37, 1998. Disponível em: <http://www.seer.ufu.br/index.php/emrevista/article/view/7834/4941 >. Acesso em: 17 jan. 2018.

CLÉMENT, P.; CASTÉRA, J. Multiple representations of human genetics in biology textbooks. In: TREAGUST, D. F; TSUI, C.-Y. (Ed.). Multiple representations in biological education. [S.1.]: Springer, 2013. p. 147-164.

DOUGHERTY, M. J. Closing the gap: inverting the genetics curriculum to ensure an informed public. The American Journal of Human Genetics, Cambridge, v. 85, n. 1, p. 6-12, 2009.

FRACALANZA, H.; AMARAL, I. A.; GOUVEIA, M. S. F. O ensino de ciências no primeiro grau. São Paulo: Atual, 1987.

FRANZOLIN, F. Conceitos de biologia na educação básica e na academia: aproximações e distanciamentos. 2012. 416 f. Tese (Doutorado em Educação) - Faculdade de Educação, Universidade de São Paulo, São Paulo, 2012.

FUNDO NACIONAL DE DESENVOLVIMENTO DA EDUCAÇÃO. Livro didático: histórico. Disponível em: < http://www.fnde.gov.br/programas/programas-do-livro/livrodidatico/historico >. Acesso em: 5 jun. 2015. 
A genética humana nos livros didáticos brasileiros ...

JACQUARD, A. Elogio da diferença. São Paulo: Martins Fontes, 1988.

JACQUARD, A.; KAHN, A. O futuro não está escrito. Lisboa: Instituto Piaget, 2001.

KRASILCHIK, M. Prática de ensino de biologia. 4. ed. São Paulo: Edusp, 2008.

LEWONTIN, R. C.; ROSE, S.; KAMIN, L. J. Not in our genes: biology, ideology and human nature. New York: Pantheon Books, 1985.

MARSHALL, C.; ROSSMAN, G. B. Designing qualitative research. Thousand Oaks: Sage, 2006.

NASCIMENTO, T. G.; MARTINS, I. O texto de genética no livro didático de ciências: uma análise retórica crítica. Investigações em Ensino de Ciências, Porto Alegre, v. 2, n. 10, p. 255-278, 2005.

OSSAK, A. L. Professor, aluno e livro didático em aulas de ciências: análise retórica dos argumentos didáticos. 2006. 129 f. Dissertação (Mestrado em Educação para a Ciência e o Ensino de Matemática) - Universidade Estadual de Maringá, Maringá, 2006.

PAPALIA, D. E.; FELDMAN, R. D. Desenvolvimento humano. 12. ed. Porto Alegre: Artmed, 2013.

PENCHASZADEH, V. B. Problemas éticos do determinismo genético. Revista Bioética, Brasília, v. 12, n. 1, p. 61-68, 2004. Disponível em: < http://revistabioetica.cfm.org.br/index. php/revista_bioetica/article/view/121/126>. Acesso em: 18 jan. 2018.

PSCHISKY, A.; MAESTRELLI, S. R. P; FERRARI, N. O tema grupos sanguíneos nos livros didáticos de biologia no período de 1960 a 2002. In: ENCONTRO NACIONAL DE PESQUISA EM EDUCAÇÃO EM CIÊNCIAS, 4., 2003, Bauru. Anais... Bauru: ABRAPEC, 2003. p. 1-11. Disponível em: < http:// fep.if.usp.br/ profis/arquivos/ivenpec/ Arquivos/Orais/ORAL123.pdf>. Acesso em: 18 jan. 2018.

SELLES, S. E.; FERREIRA, M. S. Influências histórico-culturais nas representações sobre as estações do ano em livros didáticos de ciências. Ciência $\boldsymbol{\&}$ Educação, Bauru, v. 10, n. 1, p. 101-110, 2004. Disponível em: <http://dx.doi.org/10.1590/S1516-73132004000100007>. Acesso em: 18 jan. 2018.

SILVA, C.; FERREIRA, C.; CARVALHO, G. S. Doenças genéticas e determinismo genético em manuais escolares: comparação entre Portugal e França. In: CONGRESSO INTERNACIONAL DE SAÚDE, CULTURA E SOCIEDADE, 6., 2010, Chaves. Actas... Chaves: AGIR, 2011. p. 294-309. Disponível em: <http://hdl.handle.net/1822/12657>. Acesso em: 21 jan. 2015.

- Genética humana em manuais escolares de 14 países: análise do determinismo genético e de anomalias genéticas. In: CONGRESSO NACIONAL DE EDUCAÇÃO PARA A SAÚDE, 2., 2008, Évora. Actas... Évora: CIEP, 2009. p. 523-532. Disponível em: <http:/ /hdl.handle.net/1822/8939>. Acesso em: 21 jan. 2015. 
- Que relevância é dada à influência do ambiente na expressão das doenças genéticas multifactoriais nos manuais escolares portugueses e franceses? In: CONGRESSO NACIONAL DE EDUCAÇÃO PARA SAÚDE, 3. e CONGRESSO LUSO BRASILEIRO DE EDUCAÇÃO PARA A SAÚDE, 1., 2010, Covilhã. Actas... Covilhã: Universidade da Beira Interior, 2010. p. 331-342. Disponível em: < http://hdl.handle.net/1822/11237>. Acesso em: 21 jan. 2015

TIZIOTO, P. C.; ARAÚJO, E. S. N. N. Biotecnologia e bioética nos livros didáticos. In: ENCONTRO NACIONAL DE PESQUISA EM EDUCAÇÃO EM CIÊNCIAS, 6., 2007, Florianópolis. Anais... Florianópolis: ABRAPEC, 2007.

TRIVELATO, S. L. F. Ensino de genética: um novo ponto de vista. São Paulo: Faculdade de Educação da USP, 1988.

Anexo A. Quadro com as referências dos livros analisados

\begin{tabular}{|c|c|c|}
\hline \multicolumn{3}{|c|}{ Livros Analisados } \\
\hline $\begin{array}{l}\text { Código } \\
\text { do livro }\end{array}$ & Referência completa & ISBN \\
\hline $\mathbf{A}$ & $\begin{array}{l}\text { SANTOS, F. S.; AGUILAR, J. B. V.; OLIVEIRA, M. M. A. (Org.). } \\
\text { Biologia: ser protagonista 3: professor. São Paulo: SM, } 2010 .\end{array}$ & 9788576755289 \\
\hline B & $\begin{array}{l}\text { BIZZO, N. Novas bases da biologia: o ser humano e o futuro: volu- } \\
\text { me 3: professor. São Paulo: Ática, } 2010 .\end{array}$ & 9788508130290 \\
\hline $\mathbf{C}$ & $\begin{array}{l}\text { GEWANDSZNAJDER, F; LINHARES, S. Biologia hoje: genética, } \\
\text { evolução, ecologia, professor. São Paulo: Atlas, } 2010 .\end{array}$ & 9788508129614 \\
\hline $\mathbf{D}$ & $\begin{array}{l}\text { BROCKELMANN, R. H. Conexões com a biologia 3: professor. } \\
\text { São Paulo: Moderna, } 2013 .\end{array}$ & 9788516092931 \\
\hline $\mathbf{E}$ & $\begin{array}{l}\text { AMABIS, J. M.; MARTHO, G. R. Biologia em contexto 2: adaptação } \\
\text { e continuidade da vida: livro do professor. São Paulo: Moderna, } 2013 .\end{array}$ & 9788516092856 \\
\hline F & $\begin{array}{l}\text { SILVA JR, C.; SASSON, S.; CALDINI JR, N. Biologia: volume 3, } \\
\text { professor. 10. ed. São Paulo: Saraiva, } 2012 .\end{array}$ & 9788502191921 \\
\hline G & MENDONÇA, V. L. Biologia volume 1. 2. ed. São Paulo: AJS, 2013. & 9788562482877 \\
\hline $\mathbf{H}$ & $\begin{array}{l}\text { FAVARETTO, J. A. Biologia: volume 3: professor. São Paulo: Saraiva, } \\
2013 .\end{array}$ & 9788502201002 \\
\hline $\mathbf{I}$ & $\begin{array}{l}\text { ROSSO, S.; LOPES, S. Bio volume 2: professor. 2. ed. São Paulo: } \\
\text { Saraiva, } 2012 .\end{array}$ & 9788502191846 \\
\hline
\end{tabular}

Fonte: elaborado pelos autores.

Artigo recebido em 07/12/2016. Aceito em 11/07/2017.

Endereço para contato: Universidade Federal do ABC, Centro de

Ciências Naturais e Humanas, Av. dos Estados, 5001, Bangu,

CEP 09210-170, Santo André, SP, Brasil. 